\title{
Optimal Location of SVC using Particle Swarm Optimization and Voltage Stability Indexes
}

\author{
M.N. Dazahra, F. Elmariami , A. Belfqih , J. Boukherouaa \\ Department of Electrical Networks and Static Converters, National superior School of Electricity and Mechanics, \\ Morocco
}

\begin{tabular}{l} 
Article Info \\
\hline Article history: \\
Received Jul 21, 2016 \\
Revised Oct 15, 2016 \\
Accepted Oct 29, 2016 \\
\hline
\end{tabular}

Keyword:

FACTS

Optimal location

PSO

SVC

Voltage stability

\begin{abstract}
Flexible AC transmission system are widley used in power sytems to ensure voltage stability, in virtue of their high cost the choise of the best location in electrical network is essential. The porpose of this paper is to present a new method for finding the optimal location, size and number of Static Var Compensator in order to enhace the voltage stability of electrical network. The optimal solution has been found by using the evolutionary programming algorithm, particle swarm optimization, combined with voltage stability indexes used for the estimation of the voltage collapse in power systems. The proposed algorithm has been validated by application on both simulation network model IEEE 30-Buses under different load cases and the electric network model of Casablanca region in Morocco.The results of the application have been analysed and compared in each case in order to get the optimal number of Static Var Compensator to be used.
\end{abstract}

Copyright $(9) 2016$ Institute of Advanced Engineering and Science. All rights reserved.

\section{Corresponding Author:}

Dazahra Mohamed Nouh,

Department of Electrical Networks and Static Converters,

National superior School of Electricity and Mechanics,

Road El Jadida, Km 7, BP: 8118, Oasis - Casablanca, Morocco.

Email: m.n.dazahra@gmail.com

\section{INTRODUCTION}

The electric systems are increasingly becoming more complex and heavily loaded. Along with economic and environmental constraints. One of the major concerns in power systems is voltage stability. The voltage must be maintained acceptable at all nodes of the system in normal function or after disturbance [1]. The instability of voltage is characterized by a progressive and uncontrollable decrease in voltage level caused by a disturbance, as the majority of systems operate close to their limits the control of such instability is impossible.

Different approaches have been given for the study of voltage stability [2]. The optimal value and the voltage stability limits are important for the operation of power systems, thus the necessity of defining a voltage stability indexes capable of providing reliable knowledge of the voltage stability in a power system. The value of these indexes varies in general between 0 (no load) and 1 (voltage collapse).

The FACTS (Flexible AC Transmission Systems) have been widely used to ensure the stability of voltage in power systems, The SVC (Static Var Compensator) is a shunt FATCS used to regulate voltage. SVC has many possible configurations. In this paper we use TCR-FC type of SVC [3]. Due to the expensive investment cost it is important to choose the suitable location and parameter settings of SVC to increase stability of voltage and minimize system losses. The modern heuristics optimization techniques such as evolutionary programming genetic algorithm (GA), and particle swarm optimization (PSO) are successfully implemented to solve complex problems [4-8]. However, there are more advantageous performances of the PSO than those of GA, the PSO seems to converge to its final parameter values in fewer generations than GA.The PSO method gives a better balanced mechanism and better adaptation to the global and local 
exploration abilities. Furthermore, it can be applied to solve various optimization problems in electrical systems such as stability of system and location of voltage regulator [9-12].

In the literature many researches have been done in order to find the optimal location of SVC using PSO, and to obtain the optimal type, location and setting of FACTS, optimal investment cost and annual maximum benefits [13-16]. Unfortunately the optimal number of SVC has not been mentioned in literature, so in this paper we will describe the application of PSO to find the optimal number and location of SVC using voltage stability index.

The application of the algorithm has been carried out on both the IEEE 30-bus system under different loading cases, and the electric network of Casablanca region in Morocco.

The rest of the paper is structured as follow. In section 2 the PSO is presented in general followed by a description of voltage stability index and the formulation of objective function with the application of PSO for optimal location of SVC. Results of simulation are provided in section 3.

\section{PROPOSED SOLUTION}

\subsection{Particle Swarm Optimization}

PSO was introduced by Kennedy and Eberhart [17-18]. It was inspired from social behaviors of fish schooling and bird flocking. In PSO individuals (particles) change their position in time according to their own best experience and the best experience given by their neighbors. Let D be the dimension of the search space, each particle is represented by a D-dimensional vector for example the ith particle is $X_{i}=\left(X 1_{i}, X 2_{i}, \ldots X d_{i}, \ldots ., X D_{i}\right)$ the particle with the smallest objective function value is denoted by the index Gbest (global best), each best position of particle is recorded as $P_{i}=\left(P 1_{i}, P 2_{i}, \ldots P d_{i}, \ldots . . P D_{i}\right)$ while the position change, the velocity also change flowing equation (1).

$$
V_{i}(t+1)=W_{i}(t)+C 1 \cdot R 1 .\left(P d_{i}-X d_{i}\right)+C 2 \cdot R 2 .\left(G_{b e s t}-X d_{i}\right)
$$

And the new position of the particle can be calculated by equation (2).

$$
X d_{i}(t+1)=X d_{i}(t)+V d_{i}(t+1)
$$

Where $\mathrm{W}$ is the inertia weights.

$\mathrm{C} 1$ and $\mathrm{C} 2$ are constants influencing the convergence speed of particles.

$\mathrm{R} 1$ and $\mathrm{R} 2$ are random numbers between 0 and 1 .

Velocity updates are influenced by both the best global solution associated with the lowest cost ever found by a particle and the best local solution associated with the lowest cost in the present population. If the best local solution has a cost less than the cost of the current global solution, then the best local solution replaces the best global solution. The first part of equation (1) represents the inertia of the previous velocity, the second part is the "cognition" part which represents the private thinking by itself, and the third part is the "social" part which represents the cooperation among the particles.

Using PSO offers the following advantages: it is easy to implement and there are few parameters to adjust. Hence, PSO will be a good optimization technique to use in our case for finding the optimal location and number of SVC.

\subsection{Voltage Stability Indexes}

Voltage stability indexes can provide an estimation of how a power system is close to voltage collapse, the voltage stability is described as follows: "The voltage stability is the ability of a power system to maintain steady acceptable voltages at all buses in the system at normal operating conditions and after being subjected to a disturbance." [19]. There are many voltage indexes, some are based on power flow Jacobian matrix but they require large time due to the high computational requirements. Other indexes use the elements of the admittance matrix [20-21] and some system variables such as bus voltages and power flow through lines such Lmn [22], LQP [23], and FVSI [24], the calculation of these indexes require less computational effort and are adequate for a fast diagnosing of the voltage stability. As we are looking for the optimal location of SVC to ensure stability of the network these indexes will be suitable for our case. A short description voltage stability indexes is given next. 


\subsection{Optimal Location of SVC}

The three voltage stability indexes used in this paper are The line stability index FVSI [25], LPQ [26] [27] and Lmn .These indexes are based on the concept of power flow in a transmission line. The line with index close to 1 is a line approaching to its limits, and if the value of an index exceeds 1 then one of buses connected to this line experiences a sudden voltage drop leading to a voltage collapse, the calculation of these indexes is given by equations (3), (4 ) and (5):

$$
\begin{aligned}
& F V S I_{j i}=\frac{4 \cdot Z^{2} \cdot Q_{j}}{V_{i}^{2} \cdot X} \\
& L P Q=4 \cdot\left(\frac{X}{V_{i}^{2}}\right) \cdot\left(\frac{X}{V_{i}^{2}} P_{i}^{2}+Q_{j}\right) \\
& L_{m n}=\frac{-4 * Q * \sin (\theta)}{Y_{j j} *\left(\left[V_{j} * \sin (\delta+\theta)\right]\right)^{2}}
\end{aligned}
$$

where,

$\mathrm{Z}=$ line impedance

$\mathrm{X}=$ line reactance

$\mathrm{Qj}=$ the reactive power at the receiving bus

$\mathrm{Vi}=$ voltage at the sending bus

$\mathrm{Pi}=$ active power at the sending bus.

$\theta:$ is the line impedance angle

$\delta:$ is the angle difference between the supply voltage and the receiving end voltage.

Yjj : Admittance of the line

The objective is to find the optimal location and number of SVC in order to enhance the voltage stability in an electrical network. Thus, the problem can be presented as an optimization problem.

To benefit from the advantages of the three voltage indexes FVSI, LPQ and LMN, the objective function will contain the mean average of these indexes given by equation (6) .

$$
F=\sum_{i=1}^{\text {Lines }} \frac{F V S I_{i}+L P Q_{i}+L M N_{i}}{3}
$$

The model of SVC used is presented in Figure 1. The SVC will inject or absorb its reactive power (QSVC) at the selected bus, the operating range of SVC is between -100MVar and +100MVar.
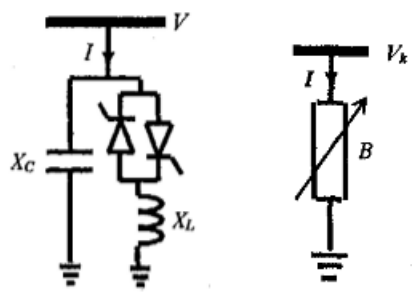

Figure 1. FC TCR Model

Let Nsvc be the number of SVC to be located. The dimension of the population Ndim is given by equation 7 :

$$
N_{\text {dim }}=2 * N_{S V C}
$$

The vector of the population will be coded as follow $[\mathrm{L} 1, \mathrm{~L} 2, \ldots \mathrm{LNdim}, \mathrm{Q} 1, \mathrm{Q} 2 \ldots \mathrm{QNdim}]$ where:

$\mathrm{Li}$ : the number of PQ bus where SVC will be inserted

Qi: the reactive power of the SVC 
The objective function is calculated using equation 6 in which voltage stability index will be calculated according to equations (3), (4) and (5), using voltage, active power, reactive power and angles given by the calculation of Newton Raphson method [28]. The best solution using PSO gives the best location of SVC and its size. The flow chart of the algorithm is presented in figure 2.

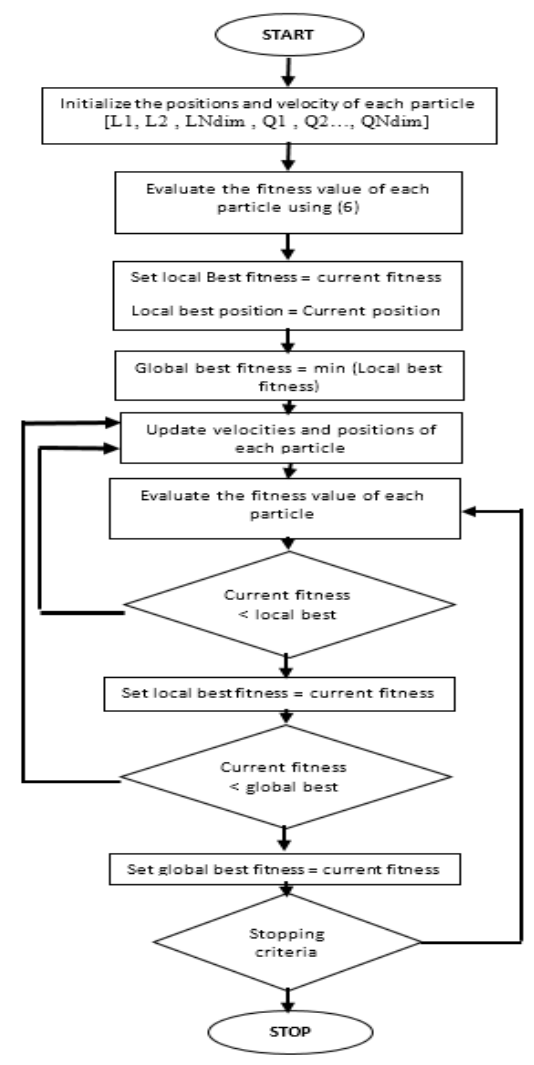

Figure 2. PSO Algorithm

\section{SIMULATIONS AND RESULTS}

\subsection{IEEE 30 Bus System Network}

In order to test the efficiency of the proposed solution, the PSO algorithm was applied to the IEEE 30 bus power system for three different cases as illustrated in Table 1, in each case the load of PQ buses increased as shown in Figure 3, the program find the optimal solution of $1 \mathrm{SVC}, 2 \mathrm{SVC}$ and 3SVC. The results of simulation are presented for each case.

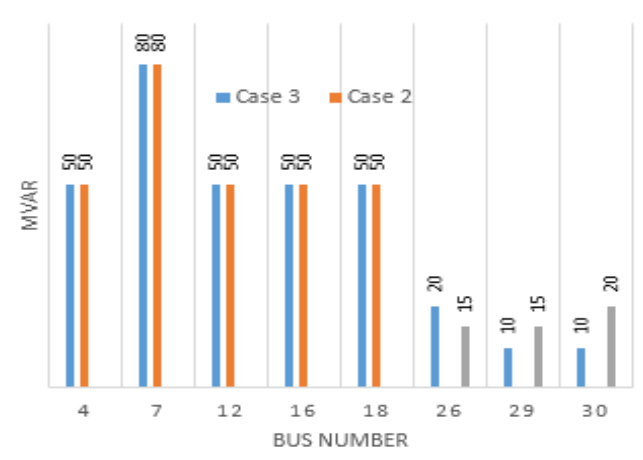

Figure 3. Load case 
The location of $2 \mathrm{SVC}$ and $3 \mathrm{SVC}$ in each case is given in Table 1, also the power loses and objective function of each case are given in Table 2.

For the first case, the difference between power losses using 2 and $3 \mathrm{SVC}$ is not important; moreover, the voltage profile is in stability zone, so the optimal number of SVC is 2 as illustrated in figure 4. In the second case, the power losses obtained with 2 SVC are bigger than those obtained with 3 SVC; also, we notice that the use of $3 \mathrm{SVC}$ led to better stability of voltage, so the optimal number of SVC is 3 as shown in Figure 5. In the last case, the results obtained with 3 SVC are better than those obtained with 2 SVC, but are not sufficients because the voltage in several buses is under $0.95 \mathrm{pu}$ as shown in figure 6 ; thus, the optimal number of SVC is 4 as shown in Figure 7.

Table 1. Optimal Location and Size of SVC in Different Cases

\begin{tabular}{cccccccc}
\hline Cases & SVC & Bus & Size (MVar) & Bus & Size (MVar) & Bus & Size (MVar) \\
\hline \multirow{2}{*}{ CASE 1 } & 2 SVC & 30 & 27.3020 & 26 & 15 & & \\
& 3 SVC & 30 & 19.9939 & 26 & 14.9995 & 29 & 14.9638 \\
\multirow{2}{*}{ CASE 2 } & 2 SVC & 18 & 58.0782 & 4 & 100 & & \\
& 3 SVC & 7 & 100 & 16 & 50.6301 & 18 & 51.6295 \\
\multirow{2}{*}{ CASE 3 } & 2 SVC & 26 & 25.3292 & 18 & 58.7378 & & \\
& 3 SVC & 4 & 100 & 26 & 25.4113 & 18 & 58.0387 \\
\hline
\end{tabular}

Table 2. Power Losses and Objective Function in Different Cases

\begin{tabular}{cccc}
\hline Cases & SVC & $\begin{array}{c}\text { Power } \\
\text { Losses(MVAR) }\end{array}$ & F (pu) \\
\hline \multirow{3}{*}{ CASE 1 } & Without SVC & 27.6113 & 0.1273 \\
& With 2 SVC & 17.9402 & 0.0488 \\
& With 3 SVC & 17.4998 & 0.0414 \\
& Without SVC & 28.0885 & 0.1301 \\
CASE 2 & With 2 SVC & 22.5850 & 0.0766 \\
& With 3 SVC & 19.7536 & 0.0572 \\
& Without SVC & 36.3234 & 0.2033 \\
CASE 3 & With 2 SVC & 25.6416 & 0.1108 \\
& With 3 SVC & 23.7044 & 0.0957 \\
\hline
\end{tabular}

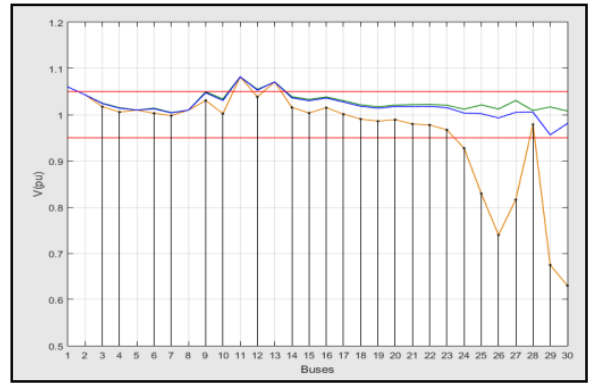

Figure 4. Voltage Profiles Case 1

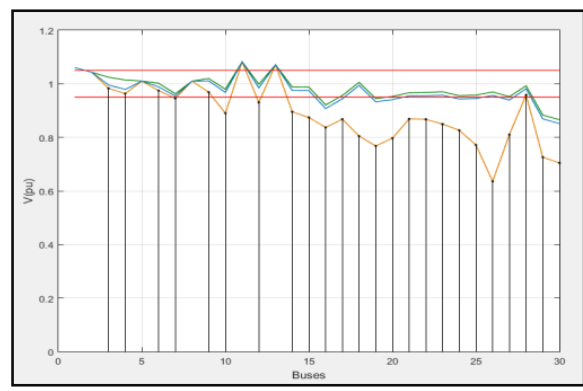

Figure 6. Voltage Profiles Case 3

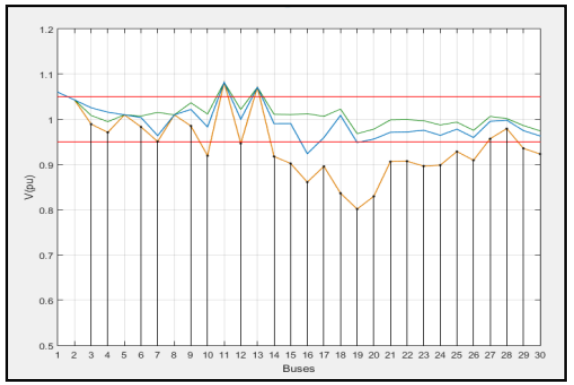

Figure 5. Voltage Profiles Case 2

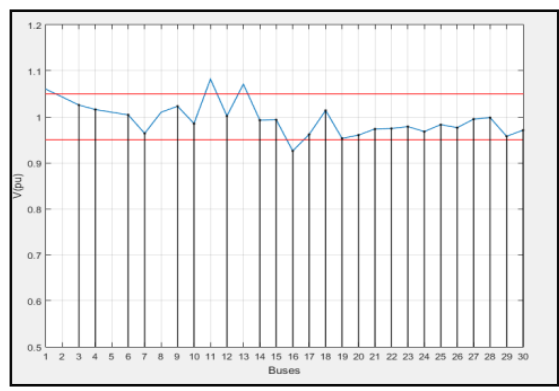

Figure 7. Voltage Profiles Case 3 Using 4 SVC 


\subsection{Electric Network of Casablanca Region}

The electric network of the city Casablanca is constituted of 6 generators and 18 load buses. The network suffers from voltage instability and violation of voltage limits in several buses $(9,16,18,20$, and 21). The results of using two, three and four SVC are given in Tables 11 and Table 12, and voltage profiles are presented in Figure 7.

Table 3. Optimal location of SVC in Casablanca case

\begin{tabular}{lcccccccr}
\hline & Bus & Size (MVar) & Bus & Size (MVar) & Bus & Size (MVar) & Bus & Size (MVar) \\
\hline 2 SVC & 4 & 69.10 & 20 & 100 & & & & \\
3 SVC & 4 & 69.10 & 20 & 100 & 9 & 100 & & \\
4 SVC & 4 & 69.01 & 20 & 100 & 9 & 100 & 21 & 80.0191 \\
\hline
\end{tabular}

Table 4. Power Losses and Objective Function in Casablanca Case

\begin{tabular}{ccc}
\hline & $\begin{array}{c}\text { Power Losses } \\
\text { (MVAR) }\end{array}$ & $\mathrm{F}(\mathrm{pu})$ \\
\hline Without SVC & 63.3274 & 0.1057 \\
With 2 SVC & 58.7489 & 0.0740 \\
With 3 SVC & 56.8470 & 0.0647 \\
With 4 SVC & 55.8382 & 0.0592 \\
\hline
\end{tabular}

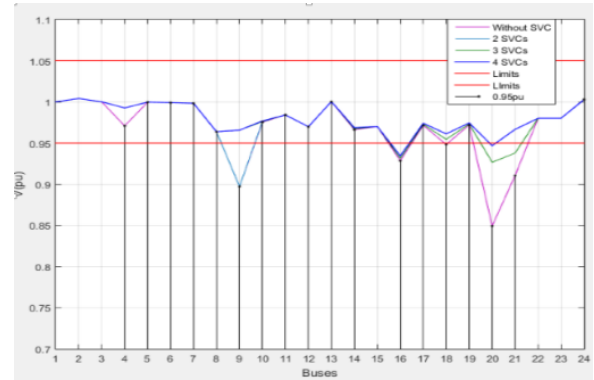

Figure 8. Voltage Profiles of Casablanca Network

From the results it's obvious that the use of $2 \mathrm{SVC}$ is insufficient. The use of $3 \mathrm{SVC}$ gives better results than $2 \mathrm{SVC}$ but voltage still drops in some buses. Therfore, the optimal number is $4 \mathrm{SVC}$.

\section{CONCLUSION}

The results described in this paper show the efficiency of the proposed solution in cases of IEEE30 bus and the electric network of Casablanca region. The program has detected the optimal location and size of the SVC needed for voltage stability. Also the number of SVC can be determined by analyzing voltage stability index and voltage profiles.

\section{REFERENCES}

[1] P. Kundur et al. "Definition and classification of power system stability IEEE/CIGRE joint task force on stability terms and definitions". IEEE Transactions on Power Systems, 2003; 19(3): 1387-1401.

[2] Ismail N.M et al. "A comparison of voltage stability indexes". Power Engineering and Optimization Conference (PEOCO). 2014

[3] Narain G. Hingoranl. "Understanding FACTS Concepts and Technology of Flexible AC Transmission Systems". The Institute of Electrical and Electronics Engineers.2000.

[4] Md. Imran Azim, Md. Fayzur Rahman. "Genetic Algorithm Based Reactive Power Management by SVC". International Journal of Electrical and Computer Engineering.2014; 4(2):200-206.

[5] Gupta, P. R. Sharma. "Optimal placement of FACTS devices for voltage stability using line indicators". Power India Conference. 2012.

[6] Rahman, A.K.M.R, et al. "Localization of FACTS devices for optimal power flow using Genetic Algorithm". Electrical Information and Communication Technology (EICT). 2013.

[7] Rao, VS, R.S. Rao. "Comparison of various methods for optimal placement of FACTS devices". Smart Electric Grid (ISEG). 2014. 
[8] Tiwari, R., et al. "Optimal location of FACTS devices for improving performance of the power systems". Power and Energy Society General Meeting.2012.

[9] Jing, Z., et al. "The application of improved particle swarm optimization algorithm in voltage stability constrained optimal power flow". Measurement, Information and Control (ICMIC).2013.

[10] Phanindra, G, C. Padmanabha Raju. "FACTS based power flow control by using particle swarm optimization technique”. Electrical, Electronics, Signals, Communication and Optimization .2015.

[11] Ravi, K., M. Rajaram. "Optimal location of FACTS devices using enhanced particle swarm optimization". Advanced Communication Control and Computing Technologies (ICACCCT), 2012.

[12] Prakash Burade, Jagdish Helonde."Optimal Location of FACTS Device on Enhancing System Security". International Journal of Electrical and Computer Engineering.2012; 2(3):309-316.

[13] S. Chansareewittaya, P. Jirapong. "Optimal allocation of multi-type FACTS controllers for total transfer capability enhancement using hybrid particle swarm optimization". Electrical Engineering/Electronics, Computer, Telecommunications and Information Technology (ECTI-CON), 2014:1-6.

[14] Malathy P, Shunmugalatha A, Thaineesh P. "Enhancement of transmission system loadability during contingency by optimal allocation of FACTS devices using particle swarm optimization". Springer. 2015: 381-92

[15] Jumaat SA, Musirin I, Othman MM, Mokhlis H. "Optimal location and sizing of SVC using particle swarm optimization technique". IEEE: $312-317$.

[16] Chang Y, Yang C. "Benefit-Based Optimal Allocation of FACTS: SVC Device for Improvement of Transmission Network Loadability". IEEE, 2007: 1-6

[17] J. Kennedy and R. Eberhart, "Particle swarm optimization". Neural Networks, 1995. Proceedings. IEEE International. 1995; 4: 1942-1948.

[18] Warren S. Goldstein. "Swarm Intelligence: Focus on Ant and Particle Swarm Optimization". I-Tech Education and Publishing. 2007.

[19] P. Kundur et al. "Definition and classification of power system stability IEEE/CIGRE joint task force on stability terms and definitions". IEEE Transactions on Power Systems. 2004: 19(3): 1387-1401.

[20] Ismail, N. A. M., et al. "A comparison of voltage stability indexes". Power Engineering and Optimization Conference (PEOCO). 2014

[21] K. Venkata Ramana Reddy, M. Padma Lalitha, PB Chennaiah. "Improvement of Voltage Profile through the Optimal Placement of FACTS Using L-Index Method". International Journal of Electrical and Computer Engineering. 2014; 4(2): 207-211.

[22] M. Moghavvemi, F. M. Omar. "Technique for contingency monitoring and voltage collapse prediction". IEE Proceedings - Generation, Transmission and Distribution.1998; 145(6): 634-640.

[23] R. Verayiah and I. Z. Abidin. "A Study on static voltage collapse proximity indicators". Power and Energy Conference. 2008: 531-536.

[24] Musirin and T. K. Abdul Rahman. "Novel fast voltage stability index (FVSI) for voltage stability analysis in power transmission system". Research and Development. 2002: 265-268.

[25] Musirin, I. and T. K. A. Rahman. "On-line voltage stability based contingency ranking using fast voltage stability index (FVSI)". Transmission and Distribution Conference and Exhibition. 2002.

[26] Suganyadevia, M. V. and C. K. Babulal. "Estimating of loadability margin of a power system by comparing Voltage Stability Indexes". Control, Automation, Communication and Energy Conservation. 2009.

[27] M. Moghavemi. "Real-time contingency evaluation and ranking technique". IEEE Procedure on Generation, Transmission and Distribution. 1998; 145(5): 517-524.

[28] H. Ambriz-Perez, E. Acha and C. R. Fuerte-Esquivel. "Advanced SVC models for Newton-Raphson load flow and Newton optimal power flow studies". in IEEE Transactions on Power Systems. 2000; 15(1): 129-136.

\section{BIOGRAPHIES OF AUTHORS}

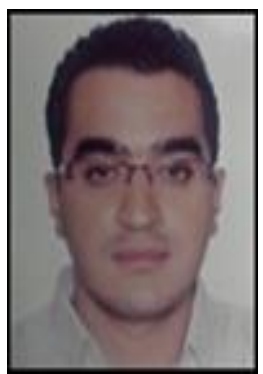

Dazahra Mohamed Nouh has obtained its state electricity engineering degree in 2012 from the superior National School of electricity and Mechanics (ENSEM).Currently Dazahra is pursuing his Ph.D. Degree programme in Electrical Power Engineering at ENSEM. He is a member of Laboratory of Electrical Networks and Static Converters in ENSEM. His research interests include power systems stability using FACTS, Smart Grid and Smart substation. 

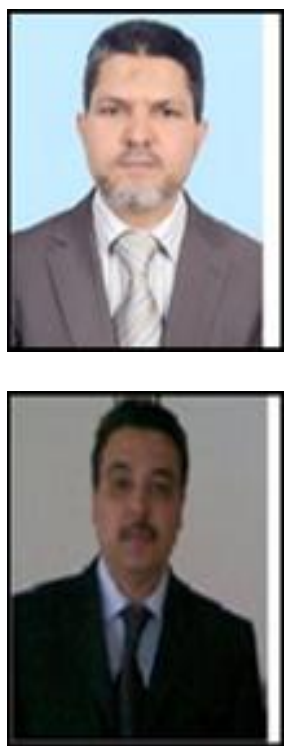

Elmariami Faycel Professor at the Superior National School of electricity and mechanics Casablanca, electrical engineering department. Member of the study team "Electrical Networks and Static Converters". He works onthe stability of the electricity network andsmart grids

Belfqih Aziz Professor at the National High School of Electricity and Mechanics (University Hassan II of Casablanca - Morocco).

$\mathrm{PhD}$, Engineer and holder of the University Habilitation searches (HDR).

Head of the research team "Electrical Networks and Static Converters. "Teacher researcher currently working on electricity network and smart grids 